\title{
'Hobbyhimmel' - an open workshop in the context of post-growth
}

An interview with Martin Langlinderer, founder of 'Hobbyhimmel' ('Hobby Heaven'), Stuttgart's first and largest open workshop, which opened its doors to the public in 2015 .

Post-growth played a central role in the project from the very beginning. Through sharing tools and machines, people are given the opportunity to produce and repair things themselves and in doing so to (re)learn old and new skills and relationships to materials and objects.

The collective use of the workshop means that tools and knowledge are shared. This not only ensures efficient use of the 'tools' as a resource but also enables mutual learning and collective doing.

In addition, the workshop allows organisations with a sustainability or social focus to use the fully equipped premises, in some cases in return for a donation, in some cases free of charge, and in this way supports the organisations' activities.

More than 40 volunteers support 'Hobbyhimmel', which is independently financed and receives no subsidies.

Interview conducted by Benedikt Schmid

Could you briefly describe for the readers what 'Hobbyhimmel' is and how the project works?

Martin Langlinderer: 'Hobbyhimmel' is the first open workshop in Stuttgart. You can imagine it as follows: a large factory hall of over $300 \mathrm{~m}^{2}$ with lots of materials, machines, tools and equipment, which we make available to the public, especially to private individuals. In the hall there are different areas for manual work with wood, metal or textiles, and also areas for electronics, 
bicycle repairs and modern production technologies - a fab lab [fabrication laboratory] with laser cutters, 3-D printers and a large CNC milling machine.

So, we offer equipment from all possible trades and crafts, and the idea is primarily that people who otherwise have no access to tools or machines or who rarely need them, use the workshop collectively. We are open seven days a week for everyone, especially in the evenings and on weekends. The workshop is only run by volunteers. We have between 40 to 50 volunteers who look after the project and run the place in their free time - opening the workshop, invoicing, being available to provide information, giving instructions and offering courses.

A particularly important point is that we are completely self-financed. That means we don't have any external funding to work with, but rather in the meanwhile - 2019 is the fourth year - the project finances itself completely independently and is also profitable.

The user groups of the workshop are very diversified. The main part is made up of private people who simply have no way of doing handicrafts at home - usually in their apartment they can't make noise, they can't get things dirty, they don't have the necessary tools and it's usually not reasonable to buy them if the tools are only used occasionally. But of course there are also other user groups. As well as the private users there are the commercial users who manufacture products or produce prototypes in the workshop. We also have training courses from private colleges or other educational providers who use the workshop, especially during the day. In addition, we have team events for companies, not forgetting the many non-profit organisations that use the workshop for their projects.

'Hobbyhimmel' is a project of the Verein zur Verbreitung Offener Werkstätten [Association for the Distribution of Open Workshops], which has dedicated itself to the goal of increasing broad social awareness of the topic of open workshops.

Can you briefly tell us what role the project plays for a post-growth economy or how 'Hobbyhimmel' can be described from a post-growth perspective?

Martin Langlinderer: For me, post-growth is the opposite of what most people currently believe: that we can produce more and more, sell more and more, consume more and more and do that at the expense of the global resources available to us. The post-growth economy is basically the antithesis, which 
says that we don't need constant growth. We must use resources much more efficiently and focus more on sufficiency, which will also make us more independent of external factors.

In our practical example it is firstly about people preferring to collectively use good, long-lasting tools rather than everyone buying their own cheap tools. With us, apart from tools people also share knowledge. If a number of people meet in one place and share their know-how then everyone can benefit from one another.

An important point apart from sharing is, secondly, the topic of repairing, so with a little effort keeping things that already exist running for longer. Repairing has become increasingly difficult in recent decades - due to poor supplies of replacement parts, planned obsolescence and other obstructions. Especially with our regular repair cafes we want to make it as easy as possible for people to get access to special tools and the necessary knowledge.

And thirdly, the topic of do-it-yourself. I have a different relationship to things I've made myself and I tend to use them longer because I know how much work I put into them and how to fix them.

In addition to private users, we also support local initiatives that deal with sustainability issues. They can use the workshop very cheaply, usually for free, and this makes it easier for them to implement their projects and activities, which are also moving towards a post-growth economy.

'Hobbyhimmel' has been supported by the 'Association for the Distribution of Open Workshops' for some time. Can you explain a bit what that's about?

Martin Langlinderer: From the very beginning the basic idea of the workshop was: one workshop is good, a lot of workshops are much better. But opening and running many workshops involves a lot of effort. Our approach is to organise this as simply as possible. This has led to the development of a social-franchise concept. That means that we make all the know-how that we have gained - all the documentation, the processes - available to other people free of cost and on an open-source basis. We also provide on-site advice so that new workshops don't have to learn everything from scratch.

That's why we founded the association, which is dedicated to the goal of helping other workshops to set up and to get established, and we provide them with anything we can give. We also collect tools through donations from private people, firms and e.g. school closures that we can pass on to 
new projects. If a number of workshops all operate according to the same principle, then the founding of each additional workshop will get easier.

And the aim is that in every urban neighbourhood low-threshold working space should be available to people, with very short distances on foot or close connections to an open workshop and very easy accessibility. That's why being open seven days a week is a cornerstone for us. In terms of price our workshop is also very accessible, which contributes towards acceptance and ultimately also the broad offerings and the diverse range of tools. We have tools and equipment in all possible fields. It's a holistic, low-threshold approach that we pursue here. Those are the components with which we try to really increase the reach and the impact of the topic of open workshops.

If you imagine that people from urban planning and local politics came to you and would like to support you in your project. What would you like those people to do?

Martin Langlinderer: Of course. I would be delighted if these people would approach us. Then we could say that we want free premises or start-up funding. Basically, I think that it's important that cities and municipalities see open workshops as important social components and start to establish them or at least promote their future development.

For me open workshops have a similar status to youth centres, swimming pools or libraries. These are all establishments that are open to everybody and are financed with public money. These establishments are an important component for society: for social cohesion, for personal development, for exchange of knowledge and so on.

They're all important establishments but they too are always only used by part of the population. And that's where I see open workshops, they're also used by certain people and like a library - to stick with this example - they contribute a great deal to knowledge generation and knowledge dissemination. Perhaps not necessarily on an intellectual basis but in the field of practical knowledge: old knowledge about handicrafts but also new technical competences. The mutual exchange is an extremely important element because otherwise, to put it bluntly, we all degenerate to simple consumers who just believe what people tell them: it's not possible to repair that, the only option is persistent gluing, there are no replacement parts, you need to throw that away and buy a new one, the fabric can only be washed three times. As a consumer, you become increasingly dumb if you're not knowl- 
edgeable about these things and then you can't make any active, conscious decisions in terms of a post-growth economy, which is about long-lasting, resource-saving products and processes. In relation to open workshops, politics and planning should use the principle of libraries as a role model: in every urban district there's a local library and open workshop and perhaps there's a large central library and a large central open workshop where there are more and specialised tools and machines. And the urban planners can then think: 'In both, important resources are shared, in one case books, in the other case machines, but in both cases knowledge' - there are so many parallels that you can draw. So, if you ask what tip I have for urban planning, then I would try to tighten this connection in their minds so that they can't forget it.

How do you imagine a transformation beyond the topic of open workshops?

Martin Langlinderer: My approach is one of small steps and setting an example. Every time I try to think consciously about what I buy and where I go. I certainly don't always get it right, in that I don't always make the most ecological, most efficient decision that favours sufficiency. For me it's also important that I no longer just use my labour in the regular economy but mainly invest it in other topics that I believe are more socially relevant. This means that I have significantly less money than I used to have but more fun and more freedom.

I sure think you can inspire people to think about things, to take small steps. But it's a long and small-scale process that's apparently not going to occur top-down. That's why we need a solid grassroots basis. There's probably not going to be much change from politics so for me it's a bottom-up process.

Many thanks for the interesting discussion. 
